\title{
Measurements of delays of gas-phase compounds in a wide variety of tubing materials due to gas-wall interactions
}

\author{
Benjamin L. Deming ${ }^{1}$, Demetrios Pagonis ${ }^{1}$, Xiaoxi Liu ${ }^{1}$, Douglas A. Day ${ }^{1}$, Ranajit Talukdar ${ }^{1}$, Jordan E. Krechmer ${ }^{2}$, \\ Joost A. de Gouw ${ }^{1}$, Jose L. Jimenez ${ }^{1}$, and Paul J. Ziemann ${ }^{1}$ \\ ${ }^{1}$ Dept. of Chemistry and Cooperative Institute for Research in Environmental Sciences, \\ University of Colorado, Boulder, CO, USA \\ ${ }^{2}$ Center for Aerosol and Cloud Chemistry, Aerodyne Research Inc., Billerica, MA, USA
}

Correspondence: Paul J. Ziemann (paul.ziemann@colorado.edu) and Jose L. Jimenez (jose.jimenez@colorado.edu)

Received: 20 January 2019 - Discussion started: 7 February 2019

Revised: 8 May 2019 - Accepted: 27 May 2019 - Published: 28 June 2019

\begin{abstract}
Losses of gas-phase compounds or delays on their transfer through tubing are important for atmospheric measurements and also provide a method to characterize and quantify gas-surface interactions. Here we expand recent results by comparing different types of Teflon and other polymer tubing, as well as glass, uncoated and coated stainless steel and aluminum, and other tubing materials by measuring the response to step increases and decreases in organic compound concentrations. All polymeric tubings showed absorptive partitioning behavior with no dependence on humidity or concentration, with PFA Teflon tubing performing best in our tests. Glass and uncoated and coated metal tubing showed very different phenomenology due to adsorptive partitioning to a finite number of surface sites. Strong dependencies on compound concentration, mixture composition, functional groups, humidity, and memory effects were observed for glass and uncoated and coated metals, which (except for Silonite-coated stainless steel) also always caused longer delays than Teflon for the compounds and concentrations tested. Delays for glass and uncoated and coated metal tubing were exacerbated at low relative humidity but reduced for RH $>20 \%$. We find that conductive PFA and Silonite tubing perform best among the materials tested for gas-plusparticle sampling lines, combining reduced gas-phase delays with good particle transmission.
\end{abstract}

\section{Introduction}

A number of studies have demonstrated that absorptive partitioning of volatile organic compounds (VOCs) into the Teflon walls of environmental chambers can affect the results of the experiments. This partitioning has been shown to be reversible and relatively fast, on a timescale of minutes (Matsunaga and Ziemann, 2010; Yeh and Ziemann, 2015; Krechmer et al., 2016; Ye et al., 2016; Huang et al., 2018). Furthermore, a recent study showed analogous absorptive partitioning of VOCs when transported through PFA (perfluoroalkoxy alkanes) Teflon tubing, with interaction parameters similar to those for FEP (fluorinated ethylene propylene) Teflon chamber walls (Pagonis et al., 2017). That work found that the tubing acted roughly as a chromatography column, effectively smearing the time profile of the measured compounds and affecting the measured concentrations. Delays of over $10 \mathrm{~min}$ were observed for realistic conditions for the least-volatile compounds $\left(C^{*} \sim 3 \times 10^{4} \mu \mathrm{g} \mathrm{m}^{-3}\right.$ ) with longer delays predicted for compounds less volatile than those measured in that study. The resulting time profiles were well-reproduced by a simple numerical chromatography model that divided the length of tubing into a series of bins in which organic compounds partitioned between the gas phase and the walls based on the vapor pressure of the organic compound and an equivalent absorbing mass of the wall $\left(C_{\mathrm{w}}, \mu \mathrm{g} \mathrm{m}^{-3}\right)$ according to Eq. (1):

$$
F_{\mathrm{w}}=\frac{1}{1+\frac{C^{*}}{C_{\mathrm{w}}}} .
$$


In this equation, $F_{\mathrm{w}}$ is the fraction of the compound partitioned to the wall at equilibrium, and $C^{*}\left(\mu \mathrm{g} \mathrm{m}^{-3}\right)$ is the saturation concentration (the vapor pressure in mass units) of the organic compound estimated using the SIMPOL.1 group contribution method (Pankow and Asher, 2008). The model code was made publicly available in the paper. They also demonstrated that partitioning depended only on the saturation concentration of the organic compound and not its specific functionality.

Although PFA Teflon is one of the most commonly used materials for gas sampling lines and instrumentation surfaces, a wide variety of materials finds use in practice for sampling gases, including other types of Teflon, PEEK (polyether ether ketone), glass, and uncoated and coated stainless steel and aluminum. Quantitative aerosol sampling requires electrically conductive tubing to avoid major losses of charged particles in Teflon tubing, and is commonly performed using uncoated stainless-steel, copper, aluminum, or polymeric tubing that has been rendered conductive by additives such as black carbon. Partitioning of semi-volatile gases to and from tubing and instrument internal surfaces can disturb gas-particle equilibrium, resulting in additional evaporation or condensation of material that may interfere with measurements. In oxidation flow reactors, such tubing and inlet delays can perturb the equilibrium of lower-volatility compounds that are thought to dominate potential aerosol mass (Palm et al., 2018). Decisions on material choice are based on a number of criteria, including but not limited to cost, weight, and electrical conductivity (for aerosols only). Also considered are the potential for gas-phase losses, delays, measurement artifacts, or memory effects, particularly when measuring low-volatility compounds or those that interact strongly with surfaces. However, systematic testing of the effects of different materials on measurements has been limited.

Here we present results of a systematic survey of 14 commonly used tubing materials with the same compounds, conditions, and measurement protocol. The effect of tubing on measurements was characterized by introducing stepfunction changes in compound concentrations while sampling through a length of tubing or directly into the instrument inlet, allowing characteristics of the tubing to be separated from any instrument effects. Through these measurements, the physical basis of partitioning in different materials can be understood, and relative performance of the different materials can be accurately compared. We aim to facilitate more informed decisions about material choice for sampling lines and inlet and instrument design and also to provide information on gas-surface interactions that may be useful to interpret studies in indoor air chemistry and other fields.

\section{Experimental}

\subsection{Absorbent tubing experiments}

A series of experiments was conducted with the polymeric tubing materials listed in Table 1. Selected 2-ketones and 1-dodecene were added to an $8 \mathrm{~m}^{3}$ FEP Teflon environmental chamber (the "VOC chamber"), which was filled with purified air from an Aadco 737 pure air generator. 2Hexanone (99\%), 2-octanone (98\%), 2-decanone (98\%), 2tridecanone $(99 \%)$, and 1-dodecene $(95 \%)$ were obtained from Aldrich, and 2-dodecanone (98\%) and 2-tetradecanone $(98 \%)$ were obtained from ChemSampCo. Solid standard compounds were weighed and added to a glass bulb, whereas liquids were measured via syringe and dispensed directly into the same bulb. These standards were then evaporated and flushed from the bulb (with heating in some cases) directly into the chamber using a $5 \mathrm{~L} \mathrm{~min}^{-1}$ stream of ultra-highpurity (UHP) $\mathrm{N}_{2}$ (Airgas). The initial concentration in the chamber was approximately $20 \mathrm{ppbv}$ (mixing ratio, $1 \mathrm{ppbv}=$ $2.06 \times 10^{10}$ molecules $\mathrm{cm}^{-3}$ for the temperature and pressure of this study) for each compound prior to gas-wall partitioning. Using Eq. (1), $C^{*}$ values estimated using SIMPOL.1 (Pankow and Asher, 2008), and a $C_{\mathrm{w}}$ value of $20 \mathrm{mg} \mathrm{m}^{-3}$ (Matsunaga and Ziemann, 2010; Yeh and Ziemann, 2015), chamber concentrations ranged from $20 \mathrm{ppbv}$ for the most volatile compound (2-hexanone) to approximately $13 \mathrm{ppbv}$ for the least volatile compound (2-tetradecanone). It should be noted, however, that since all signals were normalized to the measured chamber signal the absolute concentrations did not matter for this analysis. For experiments conducted under dry conditions the humidity was less than $0.5 \% \mathrm{RH}$, whereas for humid experiments the desired RH was achieved by adding HPLC-grade water to the chamber in the same manner as described above for the VOCs. An FEP Tefloncoated fan was run for $\sim 1$ min to guarantee complete mixing and to help achieve gas-wall partitioning equilibration in the $30 \mathrm{~min}$ period before measurements were taken. A second chamber (the "clean chamber") contained only purified air, and in some cases added water vapor. The chambers operated at room pressure $(\sim 84 \mathrm{kPa})$ and temperature $\left(23 \pm 2{ }^{\circ} \mathrm{C}\right)$, which was typically stable within $1{ }^{\circ} \mathrm{C}$, and the humidity (measured using an Amprobe THWD-5) of the two chambers differed by less than $5 \% \mathrm{RH}$.

After the chambers had equilibrated, the instrument inlet was connected to the VOC chamber via the tubing to be investigated. The flow rate through the inlet was maintained at $0.300 \pm 0.015 \mathrm{~L} \mathrm{~min}^{-1}$ with a Teflon needle valve, with any delay due to absorption in the valve being accounted for as a component of the instrument delay as described below. Once the measured signals had reached steady state, meaning that both the tubing and the instrument were equilibrated with the gas phase ("passivation"), sampling was rapidly switched to the clean chamber either before the tubing entrance (to measure the total delay due to instrument and tubing) or directly 
Table 1. Tubing materials investigated in this study.

\begin{tabular}{llrl}
\hline Material & Classification & Internal diameter (cm) & Supplier (part no.) \\
\hline PFA (perfluoroalkoxy alkanes) & Absorbent & 0.476 & McMaster-Carr (52705K34) \\
FEP (fluorinated ethylene propylene) & Absorbent & 0.476 & McMaster-Carr (2129T13) \\
PEEK (polyether ether ketone) & Absorbent & 0.381 & BGB Analytik \\
PTFE (polytetrafluoroethylene) & Absorbent & 0.476 & McMaster-Carr (5239K12) \\
C-PTFE (conductive PTFE) & Absorbent & 0.476 & Finemech (S1827-68) \\
C-PFA (conductive PFA) & Absorbent & 0.476 & Fluorotherm \\
Aluminum & Adsorbent & 0.457 & McMaster-Carr (89965K431) \\
Chromated aluminum & Adsorbent & 0.457 & As above, then chromated by \\
& & & KMG Industrial Screening \& \\
& & & Metal Finishing, Inc. \\
Electropolished steel & Adsorbent & 0.457 & Harrington Pure \\
Copper & Adsorbent & 0.483 & Grainger (2LKK2) \\
Glass & Adsorbent & 0.457 & CU glassblowing workshop \\
Silcosteel & Adsorbent & 0.457 & Restek \\
Stainless steel & Adsorbent & 0.457 & McMaster-Carr (89895K724) \\
Silonite & Adsorbent & 0.457 & Entech Instruments \\
\hline
\end{tabular}

at the instrument inlet (to measure the instrument delay only) ("depassivation").

Delays were quantified by fitting the measured depassivation time series to exponential decays. The tubing delay for these experiments is defined in Eq. (2) as the difference in the time it takes each of these curves to reach $90 \%$ of the final value:

$t_{\text {tubing, abs }}=\ln (10)\left(\tau_{\text {total }}-\tau_{\text {instrument }}\right)$,

where $t_{\text {tubing,abs }}$ is the absorptive tubing delay, $\tau_{\text {total }}$ is the fitted timescale for the tubing plus instrument depassivation, $\tau_{\text {instrument }}$ is the fitted timescale from the instrument-only depassivation, and the factor of $\ln (10)=2.3$ accounts for the difference between the fitted timescales and the time required to reach $90 \%$ depassivation. Comparing these two depassivation timescales allows the tubing delay to be decoupled from the instrument response. Each tubing delay was then normalized by the length of the piece of tubing used. Note that we use $t$ to refer to measurement delay times and $\tau$ to refer to fitted exponential timescales. A derivation of this equation can be found in the Supplement. The tubing model of Pagonis et al. (2017) was used to simulate the tubing delays expected for different values of $C_{\mathrm{w}}$ across the range of $C^{*}$ of the compounds investigated. The value of $C_{\mathrm{w}}$ resulting in the lowest error (calculated as the sum of squared residuals between modeled and measured delay curves) was chosen to be the best estimate.

\subsection{Adsorbent tubing experiments}

A series of experiments was conducted with the uncoated and coated metal and glass tubing listed in Table 1. Because adsorbent tubing can take much longer to depassivate than absorbent tubing, for these experiments measurement delays were determined from passivation curves. This approach also has more comparative value since measurements of adsorptive uptake to various materials are much more common in the literature. To avoid surface displacement processes that can occur with these materials (discussed in detail further below), only a single compound (2-hexanone, 2-decanone, or 1-dodecene) at a time was loaded into the chamber for most experiments. Each sample of tubing was depassivated using air from the clean chamber until steady-state values were reached. The tubing was then connected directly to the VOC chamber and sampled until a steady-state signal was reached. Because the time series consisted of a long period with no signal followed by an approximately sigmoidal increase in signal, the tubing delay for this adsorptive tubing, $t_{\text {tubing,ads }}$, is defined as the time it takes the measured signal to reach $50 \%$ of its steady-state value during passivation. This value was determined by selecting the points between $35 \%$ and $65 \%$ of the maximum, performing a linear fit, and solving the linear fit equation for the point at which $50 \%$ was reached. These delays were then corrected for the measured instrument response. Because $t_{\text {total }}$ is defined differently than $\tau_{\text {total}}$, adsorptive tubing delays were calculated using Eq. (3):

$t_{\text {tubing, ads }}=t_{\text {total }}-\ln (10) \tau_{\text {instrument }}$,

where $t_{\text {tubing }}$ is the tubing delay, $t_{\text {total }}$ is the measured passivation delay (calculated as described in Sect. 2.1), and $\tau_{\text {instrument }}$ is the measured instrument timescale for the compound. A derivation of this equation is given in the Supplement and an example time series is shown in Fig. S1. Although the time series are approximately sigmoidal, fitting to these types of curves resulted in poor fits for a number of experiments. The $50 \%$ benchmark used here resulted in more consistent and stable results, and although it reduced the reported delay time by $\sim 40 \%$ compared to a sigmoidal fit, it 
did not significantly affect the comparisons between materials.

\subsection{Instrumentation}

The quadrupole proton-transfer-reaction mass spectrometer (q-PTR-MS) used in this work has been previously described (de Gouw, 2007). The inlet system was reduced prior to these experiments by removing a length of Silcosteel tubing $(\sim 1 \mathrm{~m}, 1 / 8$ in. OD) and simplifying the valve system. Experiments were performed after the instrument had been pumped down and running for several days. A Vocus proton-transferreaction time-of-flight mass spectrometer (Vocus PTR-ToFMS) was also used for several experiments (Krechmer et al., 2018).

\section{Results and discussion}

\subsection{Independent absorptive versus competitive adsorptive behavior}

In surveying different tubing materials it became evident that two fundamentally different mechanisms for passivation and depassivation exist. Example time series for the passivation and depassivation of $3 \mathrm{~m}$ of FEP Teflon and $1 \mathrm{~m}$ of stainlesssteel tubing are shown in Fig. 1. Although the experimental procedures were identical, the resulting time series for the FEP Teflon (Fig. 1a and b) and stainless-steel tubing (Fig. 1c and d) show significant differences that give insight into the sorption mechanisms responsible for the tubing delays. For the FEP Teflon tubing, the approximately exponential buildin of signal during passivation (Fig. 1a) and decrease during depassivation (Fig. 1b) are consistent with an absorptive process in which each compound partitions into the tubing walls according to its vapor pressure, independent of interactions with the other compounds (Pagonis et al., 2017). This contrasts with the behavior seen for the stainless-steel tubing (Fig. 1c), in which there is a period of nearly an hour before any signal is measured, followed by a transient enhancement in the signal of the most volatile compound (2octanone) above that corresponding to its concentration in the chamber (measured separately the same day using FEP Teflon tubing as an inlet). This transient enhancement ends as the signal from the next most volatile compound in the homologous series (2-decanone) grows in, and then after that signal peaks the same pattern of signals occurs sequentially for the other 2-ketones in the series. This behavior suggests that during the period when no signal is measured the compounds in the mixture are all adsorbing to unoccupied surface adsorption sites, and that once these sites are all filled the compounds competitively displace one another according to their vapor pressures as they travel through the tubing. When an identical experiment was conducted with a single ketone no enhancement in the concentration above the chamber concentration was observed (as in Fig. S1 in the
Supplement), which we take as further evidence for competitive adsorption in the mixture experiment. This conclusion is also based on the characteristics of the time series presented in Fig. 1d, which were measured when the passivated stainless-steel tube was depassivated with humid room air. Rather than appearing as a series of exponential decays (as seen for FEP Teflon in Fig. 1b), the measured concentrations were again enhanced above the chamber concentration (by up to a factor of 40) before approaching zero (the background level for room air). In this experiment, 2-ketones adsorbed to the stainless steel were suddenly displaced by water, causing rapid desorption that led to the enhancement in measured compound concentrations. We therefore used the observation of a strong humidity dependence in measured tubing delays as additional evidence that the delays were controlled by adsorption and used it as an identifying characteristic to divide the investigated materials into two classes (Table 1): absorptive (independent VOC absorption, RH-independent, polymer-like) and adsorptive (competitive VOC adsorption, RH-dependent, metal-like).

The conclusion that there are two sorption mechanisms at play is supported by measurements of partitioning of VOCs to Teflon membrane filters and quartz filters by Mader and Pankow $(2000,2001)$. Although these authors framed their findings as adsorption in both cases, they report that partitioning to Teflon showed no humidity dependence and was not influenced by other compounds in the ambient air sampled (Mader and Pankow, 2000). In contrast, sorption to the quartz filters was strongly humidity dependent and influenced by other organic compounds (Mader and Pankow, 2001), consistent with our hypothesis that sorption to some polymeric materials occurs independent of intermolecular interactions by absorption while for some other materials it occurs by competitive adsorption. Further evidence of competitive VOC adsorption also appears in the work of Roscioli et al. (2015). These authors found that active, continuous passivation of the glass inlet and internal surfaces of an instrument with surface-active fluorinated acidic or basic compounds improved the time response for nitric acid and ammonia, respectively. Upon initial passivation they observed spikes in nitric acid or ammonia concentrations (similar to the behavior in Fig. 1d) that corresponded to displacement from surfaces.

\subsection{Measurements of absorptive delays}

The measured tubing delays of 2-ketones through polymerlike, absorbent materials (PFA, FEP, PTFE, PEEK, and conductive PTFE) under dry conditions are shown in Fig. 2. The lines are model runs fitted to the experimental data, which reproduce the observed trends well and were used to calculate the $C_{\mathrm{w}}$ values for each tubing material given in Table 2 . These $C_{\mathrm{w}}$ values may be used in conjunction with the model presented by Pagonis et al. (2017) to simulate the effects of different sampling lines on measured gas-phase concentra- 

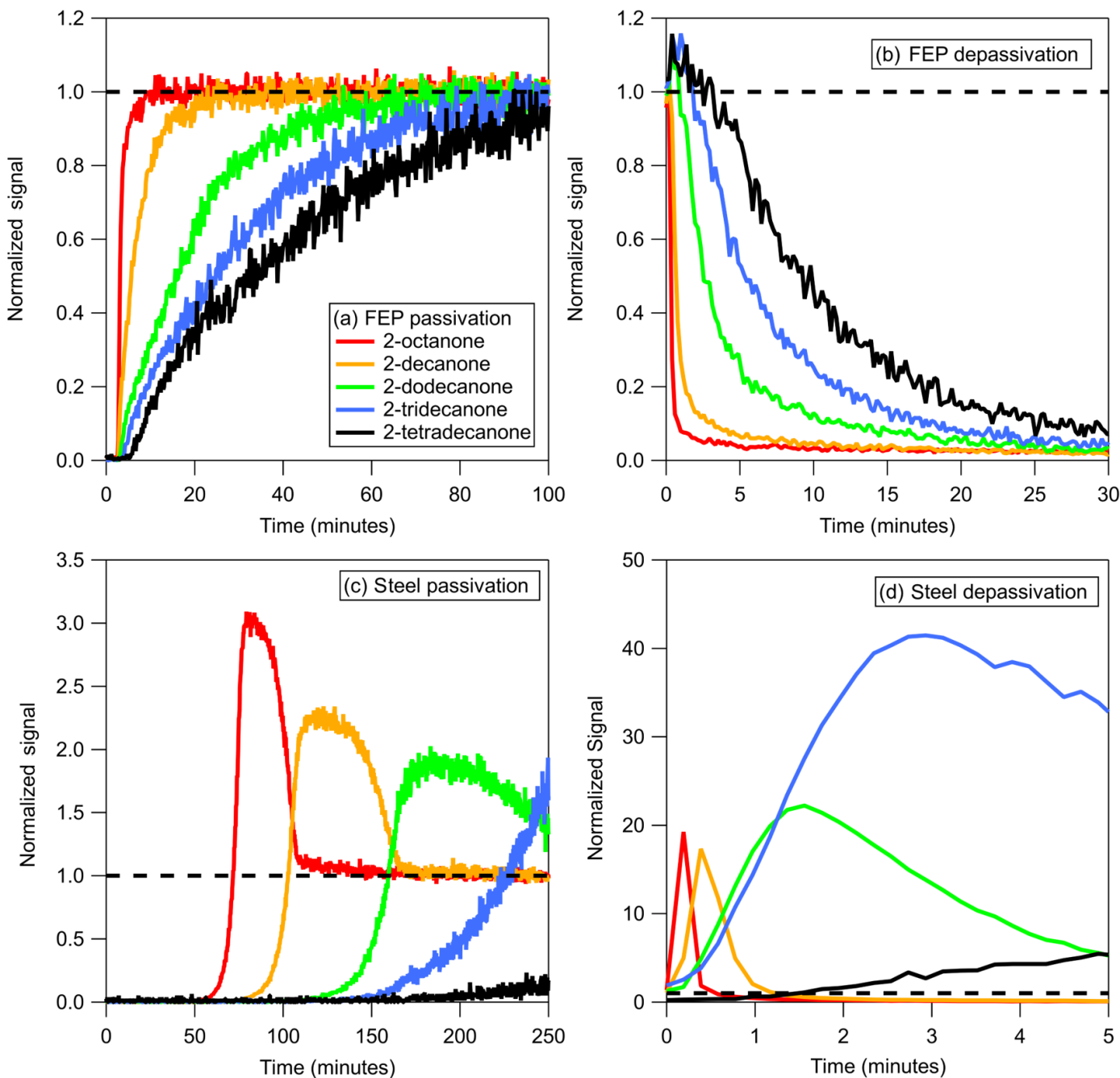

Figure 1. (a) Passivation and (b) depassivation curves measured for step function changes in a series of 2-ketones sampled through absorbent tubing ( $3 \mathrm{~m}$ of FEP Teflon). (c) Passivation and (d) depassivation curves measured for step function changes in a series of 2-ketones sampled through adsorbent tubing ( $1 \mathrm{~m}$ of stainless steel). Absorbent and adsorbent tubing was depassivated using dry and $40 \% \mathrm{RH}$ air, respectively. Note the different scales in panels (c) and (d). Signals were normalized to the values measured when sampling directly from the chamber, which were given a value of 1.0 and are represented by the dashed line in the figure.

Table 2. Fitted values of $C_{\mathrm{w}}$ for absorbent tubing materials.

\begin{tabular}{lrrr}
\hline Tubing material & $\begin{array}{r}C_{\mathrm{W}} \\
\left(\mu \mathrm{g} \mathrm{m}^{-3}\right)^{\mathrm{a}}\end{array}$ & $\begin{array}{r}\text { Internal diameter } \\
(\mathrm{cm})^{\mathrm{b}}\end{array}$ & $\begin{array}{r}\text { Internal surface area / } \\
\text { volume ratio }\left(\mathrm{cm}^{-1}\right)\end{array}$ \\
\hline PFA (perfluoroalkoxy alkanes) & $8.0 \times 10^{5}$ & 0.476 & 8.40 \\
C-PFA (conductive PFA) & $1.3 \times 10^{6}$ & 0.476 & 8.40 \\
FEP (fluorinated ethylene propylene) & $2.0 \times 10^{6}$ & 0.476 & 8.40 \\
PEEK (polyether ether ketone) & $8.0 \times 10^{6}$ & 0.381 & 10.5 \\
PTFE (polytetrafluoroethylene) & $1.2 \times 10^{7}$ & 0.476 & 8.40 \\
C-PTFE (conductive PTFE) & $1.6 \times 10^{7}$ & 0.476 & 8.40 \\
\hline
\end{tabular}

a Values of $C_{\mathrm{W}}$ for other conditions should be scaled proportionally to the surface-to-volume ratio.

${ }^{\mathrm{b}}$ Outer diameter $=0.635 \mathrm{~cm}$. 


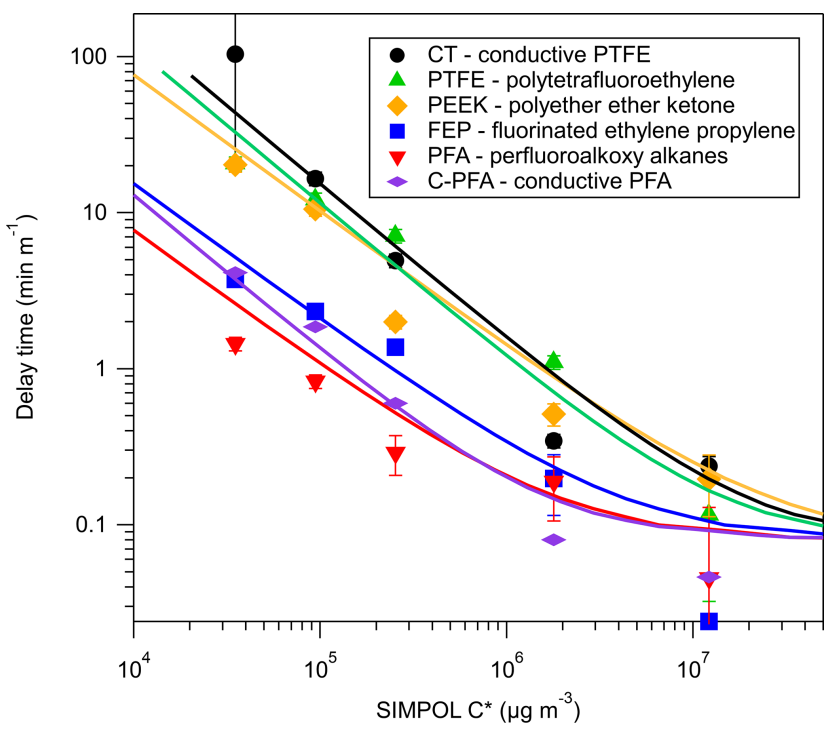

Figure 2. Delay times measured for a series of 2-ketones sampled through tubing composed of different materials. Delay times were normalized to tubing length and saturation concentrations $\left(C^{*}\right)$ of 2ketones were estimated at $298 \mathrm{~K}$ using SIMPOL.1. Error bars were propagated from exponential fits of depassivation curves. Lines are results from the Pagonis et al. (2017) chromatography model.

tions. When applied to tubes with other diameters or to these materials in other geometries $C_{\mathrm{w}}$ should be scaled by the surface-to-air volume ratio (Pagonis et al., 2017). PFA Teflon appeared to outperform FEP Teflon in terms of measurement delays, although the differences may be within our estimated error and within the level of reproducibility observed for different pieces of tubing of the same material. PEEK, PTFE, and conductive PTFE showed significantly larger delays than PFA and FEP Teflon. According to Fluorotherm (2018), PFA and FEP both have shorter polymer chain lengths and increased chain entanglements compared to PTFE. Absorption into Teflon likely occurs as gas molecules fit into spaces between the polymer chains as they thermally oscillate (Yeh et al., 2015). The fact that the polymer chains of PTFE are not as tangled as those of PFA and FEP suggests that there may be more spaces available for gases to absorb into the material, consistent with the larger value of $C_{\mathrm{w}}$ determined here. Conductive Teflon is PTFE or PFA with added black carbon to make the tubing electrically conductive and therefore appropriate for sampling aerosol. It does not appear that the added black carbon significantly changes the partitioning properties of the tubing for the compounds studied here. Transport of charged particles through conductive PFA tubing wrapped in aluminum foil (to further prevent static build-up) was comparable to sampling through copper, as shown in Fig. S3. Contrary to the commercially available conductive silicone tubing (Timko et al., 2009; Yu et al., 2009), we did not observe emission of any species from the tubing with either the VOCUS PTR-ToF-MS in this study, or with an $\mathrm{I}^{-}$chemical

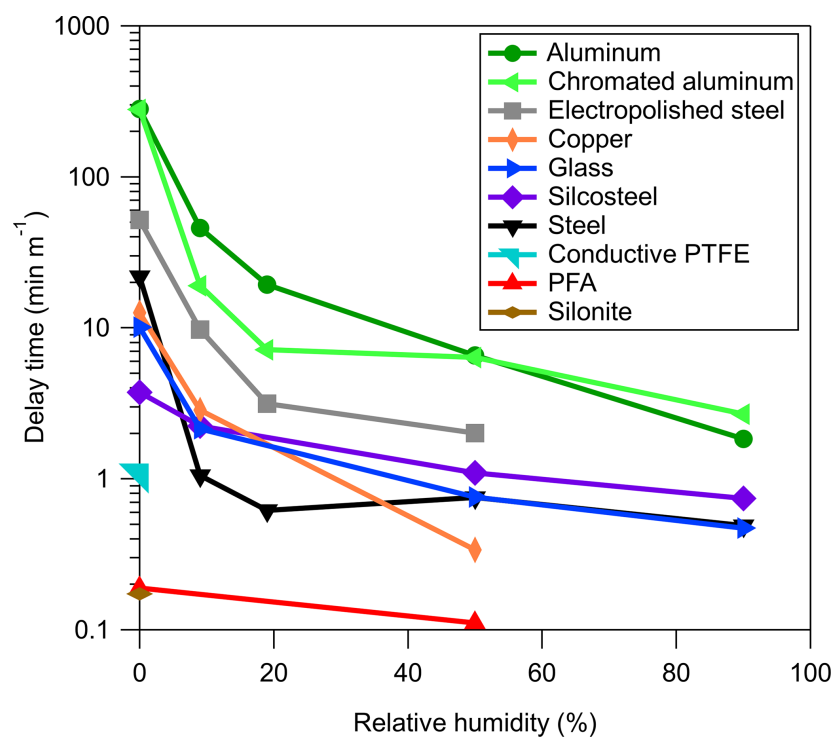

Figure 3. Humidity-dependent delay times measured for 2decanone for a series of adsorptive tubing materials. Conductive PTFE and PFA are also included for comparison.

ionization mass spectrometer (CIMS) in a related study (Liu et al., 2019). Since conductive PFA combines low interaction with gases with the electrical conductivity needed to sample particles, it is an optimal choice for applications that require joint gas-plus-aerosol sampling lines. As mentioned previously, measurement delays due to absorbent, polymer-like tubing do not exhibit humidity dependence for the species studied here, as demonstrated for PFA, FEP, and PTFE in Fig. S4. We also note that we briefly investigated a short $(0.60 \mathrm{~m})$ length of Nafion tubing $(0.178 \mathrm{~cm} \mathrm{ID)}$ using the methodology described for absorbent tubing. After $30 \mathrm{~min}$ even the most volatile ketone (2-hexanone) had only reached $30 \%$ of the chamber concentration (Fig. S2), so the experiment was aborted. It thus appears that this tubing may interfere with the sampling of polar compounds, although further investigation is needed to determine the reason.

\subsection{Measurements and characterization of adsorptive delays}

A full, quantitative investigation into the adsorptive mechanism reported here was not attempted in this paper. Instead, we discuss a few general findings that we hope will provide guidance for researchers when choosing materials for sampling lines. As discussed above, the measurement delays arising from adsorptive, or metal-like, tubing materials are highly humidity dependent. This is highlighted in Fig. 3, where an increase from $0 \%$ to $20 \% \mathrm{RH}$ generally decreases the tubing delay by about an order of magnitude. The longest measured delay times were for aluminum tubing and aluminum tubing treated with hexavalent chromate conversion coating. This coating is intended to prevent cor- 
rosion and is also used in the potential aerosol mass flow reactor (Kang et al., 2007). Delays through aluminum tubing, either with or without this coating, were long, so the coating does not appear to provide any improvement in the measured tubing delays. Stainless steel, Silcosteel, copper, and glass showed results similar to each other, among the lowest delays for the adsorptive-type tubing. Surprisingly, electropolished steel performed worse than regular stainless steel. Electropolishing creates a very smooth surface, which would be expected to reduce the number of surface sites available for adsorption. It is possible that the polishing did reduce the internal surface area of the tubing, but actually increased the number of sites by changing the elemental composition or microstructure of the surface. Alternatively, it should be noted that the steel and copper tubing used in these particular measurements had previously been used in laboratory experiments, which included sampling compounds with lower saturation concentration than 2-decanone. It is possible that some of these compounds remained adsorbed to the tubing even after depassivation with clean air, effectively conditioning the tubing by blocking some of the adsorption sites. The other tubing samples, in contrast, were bought new and used only for the adsorptive delay experiments. This could partially explain the discrepancy between normal and electropolished stainless steel. In support of this hypothesis, we note that the measurement delay through a short length of electropolished steel previously used for secondary organic aerosol (SOA) sampling in hundreds of chamber experiments (and therefore coated in low volatility organic compounds) was also measured and found to be much lower than for stainless and electropolished steel. Although some segments of the scientific community are aware of "memory effects" and the possible advantages of "conditioning" sampling lines, it is still worthwhile to raise awareness of the potentially important but unpredictable effects of tubing history on gas sampling.

Although we define the delay times slightly differently for the two types of tubing, the values for PFA Teflon and conductive Teflon are also shown in Fig. 3 for comparison. In addition to exhibiting less complex behavior, the delays produced using PFA Teflon were shorter than the majority of the tested adsorptive materials, even at high RH. Notably, Silonite tubing performed as well as PFA Teflon in terms of delays, even at low RH, and exhibited good particle transmission (Fig. S3). We note, however, that measurements can be influenced by humidity and VOC-VOC interactions.

In addition to humidity, the measured tubing delay depends on the concentration of the compound being measured, as seen in Fig. 4. At a concentration of approximately $100 \mathrm{ppbv}$ of 2-hexanone it appears that the stainless-steel tube is saturated: increasing the concentration no longer decreases the measured delay. Using the flow rate and internal surface area of the tube, this corresponds to an estimated coverage of $4 \times 10^{13}$ molecules $\mathrm{cm}^{-2}$. This is slightly less than the surface concentration of $1.4 \times 10^{14}$ molecules cm $^{-2}$ measured by Vaittinen et al. (2014) for ammonia on steel,

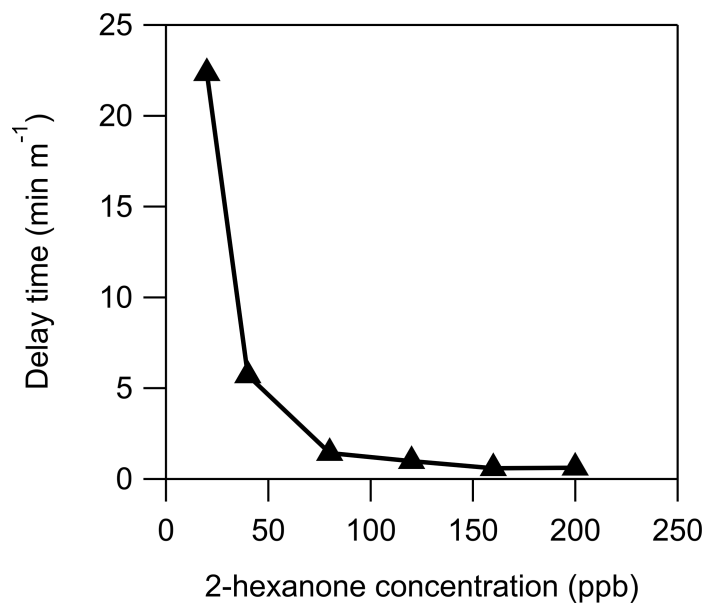

Figure 4. Measurement delays of 2-hexanone through $1 \mathrm{~m}$ of stainless steel as a function of chamber 2-hexanone concentration under dry $(\mathrm{RH}<0.5 \%)$ conditions.

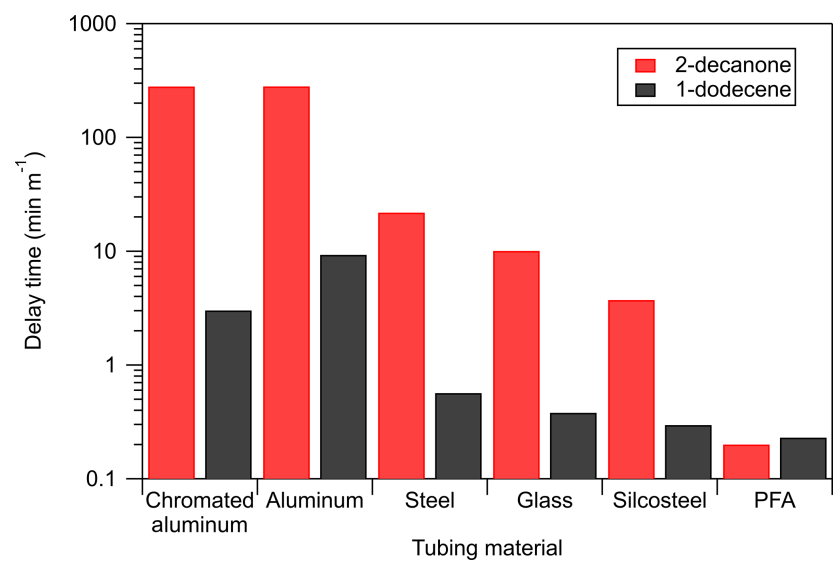

Figure 5. Comparison of measured tubing delay times for a ketone and an alkene of similar saturation concentration (2-decanone and 1-dodecene). All measurements were performed under dry conditions $(\mathrm{RH}<0.5 \%)$ with 20 ppbv of the standard in the VOC chamber.

which may be due in part to the larger size of 2-hexanone molecules. Additionally, these authors had more control over the humidity in their system than in this work, and since small changes in RH can drastically affect the measured delay time, it is possible that our value is artificially low. Furthermore, because the adsorption mechanism appears to be competitive, and this tubing had been previously exposed to organic compounds with lower vapor pressure than 2hexanone, some of those compounds may have remained sorbed to the tubing and reduced the number of adsorption sites available for 2-hexanone.

Partitioning in adsorbent tubing is also dependent on the functionality of the sorbed compound, rather than solely on saturation concentration. This was demonstrated to be the case for absorbent tubing, at least for alkenes and ketones 
(Pagonis et al., 2017). Figure 5 compares the delays measured for 2-decanone and 1-dodecene: two compounds with similar saturation concentrations as estimated from SIMPOL. $1\left(1.8 \times 10^{6}\right.$ and $\left.1.6 \times 10^{6} \mathrm{\mu g} \mathrm{m}^{-3}\right)$ but different functionality. For all but the absorptive PFA tubing the delays are much shorter for the alkene than the ketone, suggesting that more polar compounds adsorb more strongly. This is consistent with our explanation of adsorption as the mechanism behind these delays, as adhesion to surface sites may depend on molecular weight, polarity, or even specific functionality. It is also consistent with the ability of water vapor to displace the ketones from the sites. It should be noted that the alkene delay measurements are more uncertain than the ketone measurements due to lower instrument sensitivity, but because the delay times typically differ by an order of magnitude or more we conclude that this functionality dependence is real.

\section{Conclusions}

Building on the work of Pagonis et al. (2017), we measured the tubing delays associated with sampling VOCs through a wide array of tubing materials. It was found that delays through polymer tubing are controlled by independent absorption, whereas delays in glass and uncoated and coated metal tubing are controlled by competitive adsorption. Absorbent tubing exhibits delays that can be characterized by an effective absorbing mass concentration of the wall, which we report here for six different materials, and which can be scaled for other tubing sizes or material geometries. These values can be used in the model provided by Pagonis et al. (2017) to predict the effects of sampling lines on measurements. Furthermore, delays in absorbent tubing do not show humidity, concentration, or functionality dependence over the ranges of these variables tested here. This is in contrast to adsorbent tubing, which demonstrates a strong dependence on these three factors in addition to generally longer delay times. We therefore recommend the use of absorbent tubing when possible to simplify analysis of gases. If they can be used, PFA and FEP Teflon appear to be the best choices for minimizing measurement delays. If adsorbent tubing must be used, delays can be minimized by ensuring the RH is maintained above $20 \%$. It should also be emphasized that use of adsorbent tubing can result in large memory effects and sampling artifacts, particularly upon changes in RH. Conductive PFA tubing and Silonite were shown to be the best choices for simultaneous gas and particle sampling; however, we note that the Silonite purchased here cost 2.5 times that of conductive PFA per foot. Conductive FEP, although not tested in this work, may combine good gas and particle transmission at approximately half the price of conductive PFA. Despite these recommendations, adsorbent materials will no doubt continue to find use in sampling lines and instrument internal surfaces. Further work is therefore necessary to more completely characterize the relationships put forth in this paper.
Specifically, the effects of functionality and concentration should be analyzed more fully to develop a better working model for the mechanism of these measured delays.

Code and data availability. Data for each figure and model code are available for download at http://cires1.colorado.edu/jimenez/ group_pubs.html (last access: 25 May 2019).

Supplement. The supplement related to this article is available online at: https://doi.org/10.5194/amt-12-3453-2019-supplement.

Author contributions. BLD, DP, JAdG, JLJ, and PJZ designed the study. BLD, DP, DAD, and JEK conducted the experiments. BLD, DP, XL, RT, and JAdG participated in the data analysis. BLD wrote the paper, which was revised by DP, JAdG, JLJ, and PJZ.

Competing interests. The authors declare that they have no conflict of interest.

Acknowledgements. We thank the ToF-CIMS user community, Bill Brune, and Eric Apel for useful discussions.

Financial support. This research has been supported by the U.S. Department of Energy, Biological and Environmental Research (grant no. DE-SC0016559) and the Alfred P. Sloan Foundation (grant nos. G-2016-7173 and G-2018-10071).

Review statement. This paper was edited by Fred Stroh and reviewed by two anonymous referees.

\section{References}

De Gouw, J. and Warneke, C.: Measurements of volatile organic compounds in the earth's atmosphere using proton-transferreaction mass spectrometry, Mass Spectrom. Rev., 26, 223-257, https://doi.org/10.1002/mas.20119, 2007.

Fluorotherm: FEP Properties: available at: https://www. fluorotherm.com/technical-information/materials-overview/ fep-properties/; PFA Properties: available at: https://www. fluorotherm.com/technical-information/materials-overview/ pfa-properties/, last access: 2 July 2018.

Huang, Y., Zhao, R., Charan, S. M., Kenseth, C. M., Zhang, X., and Seinfeld, J. H.: Unified theory of vapor-wall mass transport in Teflon-walled environmental chambers, Environ. Sci. Technol., 52, 2134-2142, https://doi.org/10.1021/acs.est.7b05575, 2018.

Kang, E., Root, M. J., Toohey, D. W., and Brune, W. H.: Introducing the concept of Potential Aerosol Mass (PAM), Atmos. Chem. Phys., 7, 5727-5744, https://doi.org/10.5194/acp-7-5727-2007, 2007. 
Krechmer, J. E., Pagonis, D., Ziemann, P. J., and Jimenez, J. L.: Quantification of gas-wall partitioning in Teflon environmental chambers using rapid bursts of low-volatility oxidized species generated in-situ, Environ. Sci. Technol., 50, 5757-5765, https://doi.org/10.1021/acs.est.6b00606, 2016.

Krechmer, J. E., Lopez-Hilfiker, F., Koss, A., Hutterli, M., Stoermer, C., Deming, B., Kimmel, J., Warneke, C., Holzinger, R., Jayne, J., Worsnop, D., Fuhrer, K., Gonin, M., and de Gouw, J.: Evaluation of a new reagent-ion source and focusing ion-molecule reactor for use in proton-transferreaction mass spectrometry, Anal. Chem., 90, 12011-12018, https://doi.org/10.1021/acs.analchem.8b02641, 2018.

Liu, X., Deming, B., Pagonis, D., Day, D. A., Palm, B. B., Talukdar, R., Roberts, J. M., Veres, P. R., Krechmer, J. E., Thornton, J. A., de Gouw, J. A., Ziemann, P. J., and Jimenez, J. L.: Effects of Gas-Wall Interactions on Measurements of Semivolatile Compounds and Small Polar Molecules, Atmos. Meas. Tech. Discuss., https://doi.org/10.5194/amt-2019-52, in review, 2019.

Mader, B. T. and Pankow, J. F.: Gas/solid partitioning of semivolatile organic compounds (SOCs) to air filters. 1. Partitioning of polychlorinated dibenzodioxins, polychlorinated dibenzofurans and polycyclic aromatic hydrocarbons to teflon membrane filters, Atmos. Environ., 34, 4879-4887, https://doi.org/10.1016/S1352-2310(00)00241-7, 2000.

Mader, B. T. and Pankow, J. F.: Gas/solid partitioning of semivolatile organic compounds (SOCs) to air filters. 2. Partitioning of polychlorinated dibenzodioxins, polychlorinated dibenzofurans, and polycyclic aromatic hydrocarbons to quartz fiber filters, Atmos. Environ., 35, 1217-1223, https://doi.org/10.1016/S1352-2310(00)00398-8, 2001.

Matsunaga, A. and Ziemann, P. J.: Gas-wall partitioning of organic compounds in a Teflon film chamber and potential effects on reaction product and aerosol yield measurements, Aerosol Sci. Technol., 44, 881-892, https://doi.org/10.1080/02786826.2010.501044, 2010.

Pagonis, D., Krechmer, J. E., de Gouw, J., Jimenez, J. L., and Ziemann, P. J.: Effects of gas-wall partitioning in Teflon tubing and instrumentation on time-resolved measurements of gasphase organic compounds, Atmos. Meas. Tech., 10, 4687-4696, https://doi.org/10.5194/amt-10-4687-2017, 2017.
Palm, B. B., de Sá, S. S., Day, D. A., Campuzano-Jost, P., Hu, W., Seco, R., Sjostedt, S. J., Park, J.-H., Guenther, A. B., Kim, S., Brito, J., Wurm, F., Artaxo, P., Thalman, R., Wang, J., Yee, L. D., Wernis, R., Isaacman-VanWertz, G., Goldstein, A. H., Liu, Y., Springston, S. R., Souza, R., Newburn, M. K., Alexander, M. L., Martin, S. T., and Jimenez, J. L.: Secondary organic aerosol formation from ambient air in an oxidation flow reactor in central Amazonia, Atmos. Chem. Phys., 18, 467-493, https://doi.org/10.5194/acp-18-467-2018, 2018.

Pankow, J. F. and Asher, W. E.: SIMPOL.1: a simple group contribution method for predicting vapor pressures and enthalpies of vaporization of multifunctional organic compounds, Atmos. Chem. Phys., 8, 2773-2796, https://doi.org/10.5194/acp-8-27732008, 2008.

Roscioli, J. R., Zahniser, M. S., Nelson, D. D., Herndon, S. C., and Kolb, C. E.: New approaches to measuring sticky molecules: improvement of instrumental response times using active passivation, J. Phys. Chem. A, 120, 1347-1357, https://doi.org/10.1021/acs.jpca.5b04395, 2016.

Timko, M. T., Yu, Z., Kroll, J., Jayne, J. T., Worsnop, D. R., and Miake-Lye, R. C.: Sampling artifacts from conductive silicone tubing, Aerosol Sci. Technol., 43, 855-865, https://doi.org/10.1080/02786820902984811, 2009.

Vaittinen, O., Metsälä, M., Persijn, S., Vainio, M., and Halonen, L.: Adsorption of ammonia on treated stainless steel and polymer surfaces, Appl. Phys. B, 115, 185-196, https://doi.org/10.1007/s00340-013-5590-3, 2014.

Ye, P., Ding, X., Hakala, J., Hofbauer, V., Robinson, E. S., and Donahue, N. M.: Vapor wall loss of semi-volatile organic compounds in a Teflon chamber, Aerosol Sci. Technol., 50, 822-834, https://doi.org/10.1080/02786826.2016.1195905, 2016.

Yeh, G. K. and Ziemann, P. J.: Gas-wall partitioning of oxygenated organic compounds: Measurements, structureactivity relationships, and correlation with gas chromatographic retention factor, Aerosol Sci. Technol., 49, 727-738, https://doi.org/10.1080/02786826.2015.1068427, 2015.

Yu, Y., Alexander, M. L., Perraud, V., Bruns, E. A., Johnson, S. N., Ezell, M. J., and Finlayson-Pitts, B. J.: Contamination from electrically conductive silicone tubing during aerosol chemical analysis, Atmos. Environ., 43, 2836-2839, https://doi.org/10.1016/j.atmosenv.2009.02.014, 2009. 